\title{
Research on Modularized Quick Response Production Mode of Garment Enterprises
}

\author{
Shufang Song \\ Art and Clothing College \\ Tianjin Polytechnic University \\ Tianjin 300160, China \\ E-mail: 1982songshufang@163.com
}

\begin{abstract}
This text mainly introduces the connotation and function of modularized quick response production mode of garment enterprise, explores into the meaning of application of quick response production mode in garment enterprise, expounds on the key technology of quick response production mode of garment enterprise, analyses the application of quick response production mode, and brings forward the research direction of quick response production mode of garment field in the future.

Keywords: Modularization, Garment enterprises, Quick response, Production mode

With the intensified market competition and continuous change of consumption concepts, the pursuit of diversified and individual products has become the consumption tendency in garment field, and the traditional production system can no longer meet the market requirements. In order to adapt to the above changes, the garment enterprises have to adopt the advanced Quick Response Production Mode as per the market demand.

Modularized production mode is one of the main production methods of modernized garment enterprises in the 21st century (Ko, 1998, pp. 11-18). As a brand-new production mode, Mass Customization combines the advantages of customization and mass production, which can not only meet the individual demand of customers, but also guarantee low cost and short delivery date (King, 1998, pp. 37-38). This text will make initial exploration into the application of Mass Customization in garment field from the angle of quick response production mode.
\end{abstract}

\section{Connotation of modularized quick response production mode}

Quick response production describes the production system with short production period (Lv, 2004,pp. 41-42),acute response to market, and strong adaptability which can vary the products as per market demand. Mass Customization is the effective mode to realize quick response production in garment field, which aims to achieve the standardization and modularization of product components. It is reflected through following aspects.

\subsection{Component classification and systematization}

Summarize the parts that can be standardized, incorporate the similar parts, and decompose and allocate the common garment parts and craft through the analysis of various garment parts, components and accessories.

\subsection{Design Standardization and Normalization}

The purpose of standardization is to control and reduce the cost through uniform and determined solution and use of standard components; Normalization is to analyze the components, incorporate and classify the similar parts to increase the use frequency of components.

\subsection{Product family design}

The comprising modules of product structure can rapidly form the end product; module organization enables the design, production and sales department to reflect the customer's demand with uniform method; realize the integration of whole process of product design as information integration platform.

\subsection{Modularized and unitized design}

Modularized design is to make functional analysis into products with different functions and specification in certain range, classify and design a series of functional modules, and compose different products through the choice and combination of modules to meet various demands. The garment design and production module is divided according to product family (Wu, 2001, pp. 40-42). 


\section{Function of modularized quick response system}

\subsection{Quick design function}

Quick design can combine module contents of every component to create corresponding design documents and process flow, and search, edit and add new content of pattern design and process flow design.

\subsection{Quick craft design function}

Quick craft design function can automatically choose the default settings from database and finish corresponding process sheets according to the pattern parameter variation. The process document of craft database includes working procedures, labor hour, equipment, type of work, etc.

\subsection{Pipeline balancing design function}

Through the functional module operation of pipeline balancing design, production cycle time can be calculated and further pipeline balancing design can be done (Wang, 2003, pp. 16-18). Pipeline balancing design is exported in blank form, and the pipeline design results can be altered and edited by man.

\section{Meaning of quick response production mode application in garment enterprise}

With the intensified market competition of garment market, the traditional strapping garment production mode can no longer meet the market demand. Therefore, in order to meet the development requirement of social economy, garment enterprise shall adopt the production mode in compliance with quick response system, which has following advantages:

(1) It can save operation time, reduce unnecessary non-production time consumption, and effectively increase working efficiency and labor productivity;

(2) It can improve quick response capability for production, and vary the product category to meet the diversified and small-quantity garment production demand;

(3) It can greatly reduce the production cycle, fasten the production flow, and meet the deadline easily;

(4) It will have lesser loss for species variation, and have strong adaptability towards small-quantity production;

(5) It can effectively increase the utilization rate of production site; improve the working environment, which is beneficial for production measurement and monitoring.

However, modularized production mode has low utilization rate of equipment, so it has higher requirements for workers' skill. Workers have to stand during the process, so it also has great production intensity.

\section{Key technology of quick response production in garment enterprise}

The crux of modularized quick production design lies in the standardization, modularization of garment design and information integration of enterprise design and production, etc.

\subsection{Module content}

Standardized module includes men's suit, men's shirt, women's suit and trousers, etc. Variation module includes the layer-by-layer decomposition of various garment processes in tree-logic form in compliance with the combination sequence of components; Component module includes the design, craft and production flow of the key components such as collar, sleeve, placket, body and pocket, etc; Part module includes various design, craft and production flow of edge, ironing, etc; Craft swatch module includes the craft requirements and sewing constitution of standard design, etc.

\subsection{Collocation of garment knowledge and systematical design}

First collect and collocate various pattern design and craft, determine various craft parameter in standard working condition; Then decompose the design, production and combination craft of each component in logic tree form, collect design and craft as much as possible, and divide the relevant documents into database with corresponding code; demonstrate the collected craft knowledge in normative form and establish relationship between different data to guarantee the coherence of all the relevant data in case of parameter variation(Zhang, 2004,pp. 35-37).

\subsection{Characteristics of modularized design}

Develop the system with the gradual perfect method from simple to complex according to garment production characteristics. To choose the typical product such as suites, shirts, etc for multi-aspect design of pattern and process craft, and enlarge and increase component module and sub module according to diversified products.

For instance, men's suite is a typical product of garment species with comparatively stable pattern but complex craft and production design. Its production design can be divided into 5 modules-collar, sleeve, body, pocket and combination. Combine each module through combination module and each module can be divided into several sub modules, for instance, the main body module can be divided into front body module and back body module, and the front body module can be further divided into..., until the components and craft can no longer be divided. Every part can be moved, adjusted and innovated, and combined into integrated production design through combination. 


\subsection{Mathematical model of pipeline balancing design}

Optimum pipeline design is to assign the separated working procedure to corresponding workers as per their type of work, and make the accumulated production period of each work close to pipeline takt time. The objective function of optimum design of pipeline balancing is: $G=\min \left[n \sum k\left(Q_{k} \times N_{k}-R\right)\right](k=1,2, \ldots, n)$. Among the formula, $R$ denotes pipeline takt time, $\mathrm{R}=\mathrm{T} / \mathrm{n}$; $\mathrm{T}$ means the total working hours of unit product; $\mathrm{n}$ is the total number of workers; $\mathrm{N}_{\mathrm{k}}$ is the accumulated production period of the No.K worker; K means the pipeline workers; $\mathrm{Q}_{\mathrm{k}}$ denotes the proficiency coefficient of every worker.

Pipeline balancing design can calculate the take time and production planning in accordance with the number of workers, the proficiency coefficient of every worker, equipment and tool quantity, equipment composition and processing hour, etc, and formulate optimize the initial production scheme (Zheng,2001,pp. 38-41).

\section{Application of quick response production mode in garment enterprises}

\subsection{System module for quick production design}

Establish typical module library of various patterns and relevant component library, part library and process sheets, etc through analysis of existing garment products. The operators can edit and modify the typical design and stock pattern, create new pattern and corresponding craft and process, and optimize the pipeline planning.

\subsection{Search, browse and modify the system}

The system provides browsing and searching functions, which enables the operators to visit and modify the craft and pattern etc. and add new data easily.

\subsection{Computing compilation program}

After the input of anticipated efficiency, the system can work out and optimize production arrangement scheme, and rapidly provide the reasonable production design planning under set conditions.

\section{Prospects}

With the system support, further relationship with CAD and ERP softwares can be established, rapid design and production can be organized according to capital, technology and product species of enterprise and in compliance with the customers' demand, which will save more time and improve the competitiveness of the enterprise. Garment quick response mechanism can only be established through the combination of garment knowledge and information technology, and the application of advanced modern production concept into the garment production.

\section{References}

King R E.(1998). Analysis of Apparel Production System to Support Quick Response Peplenishment. National Textile Center Research Briefs, 8, 37-38.

Ko E and Kincade D H.(1998). Product line characteristics as determinants of quick response implementation for US apparel manufacturer. Clothing and Textile Research Journal, 16(1), 11-18.

Lv X and Chen X. (2004). Study on Mass Customization Mode of Apparel Industry. Shanghai Textile Science \& Technology, 32(4), 41-42.

Wang D., Hu L., Ling D., et al. (2003). The Schedule for Garment Sewing Assembly line. Journal of Textile Research, 24(4), 16-18.

Wu D.(2001). New Production Mode of Modern Enterprise-Mass Customization. Group Technology \& Production Modernization, 18(4), 40-42.

Zhang X. and Li K.(2004).The Configuration Design in Apparel Mass Customization Production. Shandong Textile Science \& Technology, 45(4), 35-37.

Zheng Q., Xu Y., Hou L., et al.(2001). The Research on Modular Design Technology in Automobile. Panel Dies Or iented to Rapid Manufacturing, 18(3), 38-41. 